\title{
Artista invitado
}

\section{Guest artist}

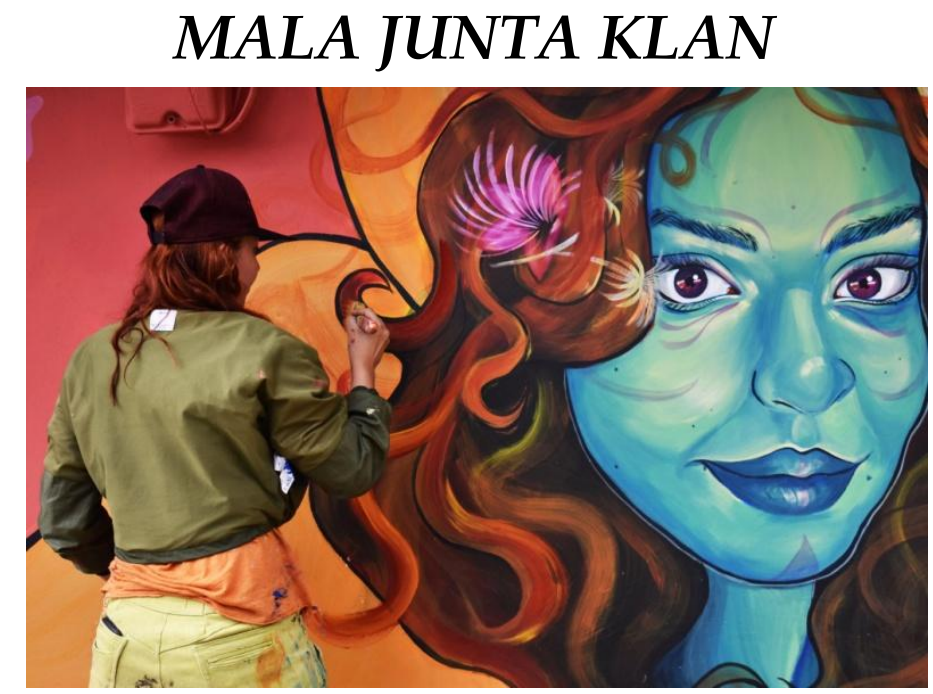

Fotografía del trabajo artístico, 2019

Mala JuntaKlan ${ }^{1}$ es un colectivo de mujeres artistas urbanas de Cali, organizado en octubre de 2018 con el propósito de hacer una juntanza femenina para crecer, compartir proyectos y experiencias, construir, aprender y proyectarse cada una, como artistas y como compañeras, desde su propia diversidad pero con la fuerza y el poder de lo colectivo, para la gestión cultural/artística y la incidencia en diferentes espacios de la ciudad.

Desde distintas apuestas, como el muralismo y el grafiti, lo que las une es el arte urbano entendido como la posibilidad de hacer intervenciones artísticas en la calle que pueden ser apreciadas e interpretadas libremente, y múltiples veces, por la ciudadanía en general, sin necesidad de pagar o ingresar a espacios cerrados como museos o galerías de arte. Como colectivo de mujeres que pintan en las calles, buscan generar dinámicas de empoderamiento desde la escena femenina, transformar desde la acción las distintas adversidades o particularidades que viven en la calle por ser mujeres.

En Mala Junta Klan convergen 13 mujeres: Cora, Violenta, Teca, Ionic, Dani Negret, Nandy, Ángel, Canelita, Jho, Anto, Germen, Yina Obando y Solvey, con diferentes profesiones como artistas plásticas, visuales, ilustradoras, diseñadoras y gestoras

1 Contacto: https://www.instagram.com/malajuntaklan/ - \#MJKLAN \#malajuntaklan 
Gutiérrez-Cárdenas

culturales, etc., quienes desde la autogestión realizan intervenciones en diferentes espacios de la ciudad, participando además en mingas y procesos comunitarios, en diversos territorios del centro, el oriente, la ladera de Cali y otras ciudades del país, con temáticas acordes a la realidad del contexto urbano, y desde sus propias perspectivas.

También han participado y gestionado, junto a la Mesa de Gráfica Urbana de Cali, festivales de arte urbano como el Borondo, y han sido invitadas especiales al conversatorio "Mujeres en el arte urbano", en el marco del Festival de Gráfica Urbana para la Paz Graficalia en 2019, organizado por la Secretaría de Paz y Cultura Ciudadana de la Alcaldía de Santiago de Cali.

Asumen la intervención artística como la posibilidad de expresar y plasmar diferentes formas de ser, diversas ideas, y filosofías de vida para generar en el público sensaciones, emociones, reflexiones a través de la combinación de formas y colores, abordando múltiples temáticas como la construcción de paz, la construcción comunitaria, la igualdad salarial, el impuesto rosa, el empoderamiento femenino, entre otras.

Entre sus proyectos están la creación de obras para respaldar iniciativas solidarias dentro y fuera del Colectivo, y también la creación de una obra en conjunto con diferentes artistas urbanas del país.

Alejandra Gutiérrez-Cárdenas. Universidad del Valle. Cali, Colombia. alejandra.gutierrez@correounivalle.edu.co.

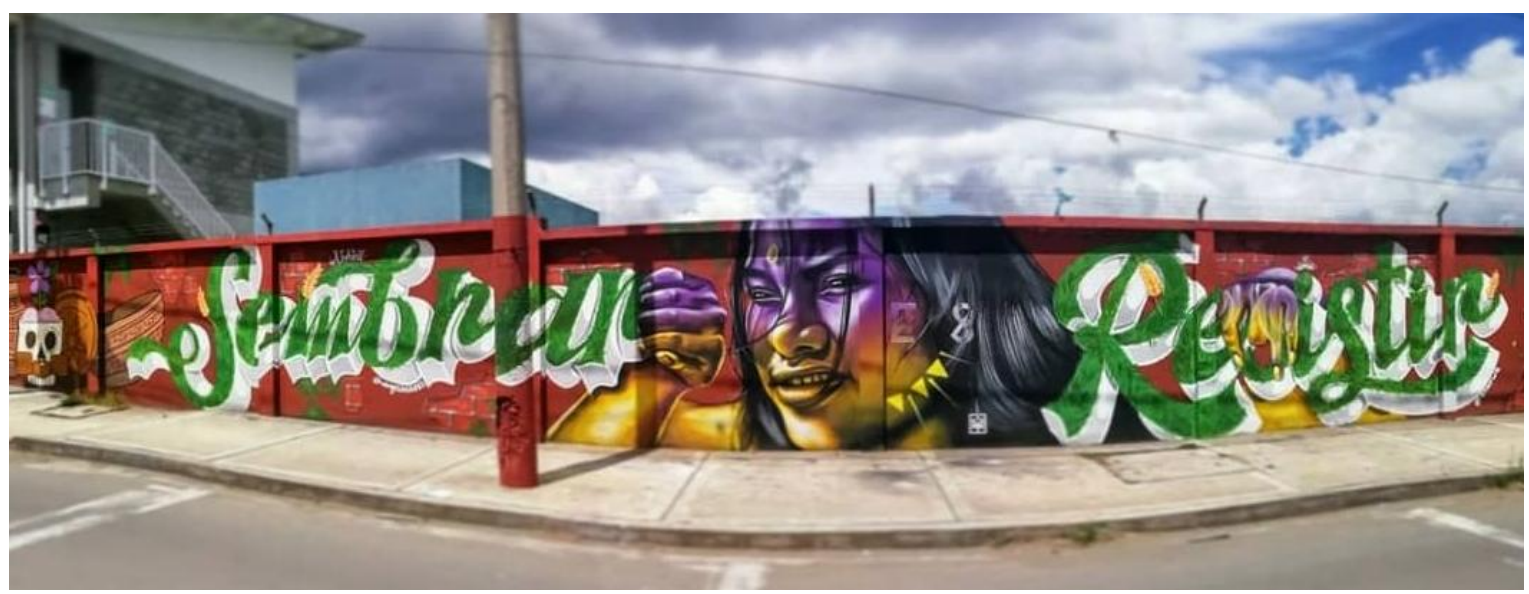

Minga de muralismo y arte rural y Cueche Jongovito Mala Junta Klan 


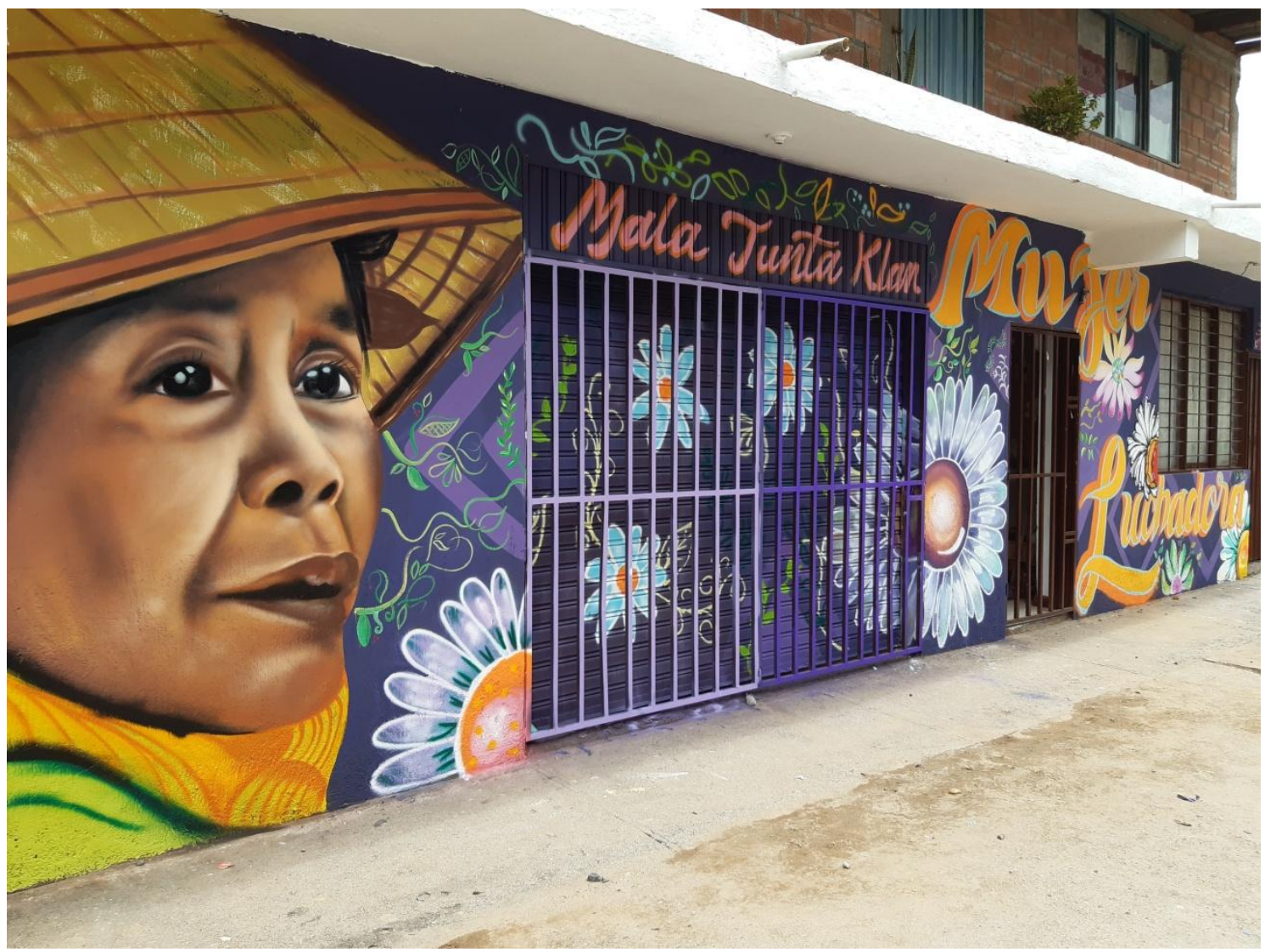

Comuna 18

Mala Junta Klan

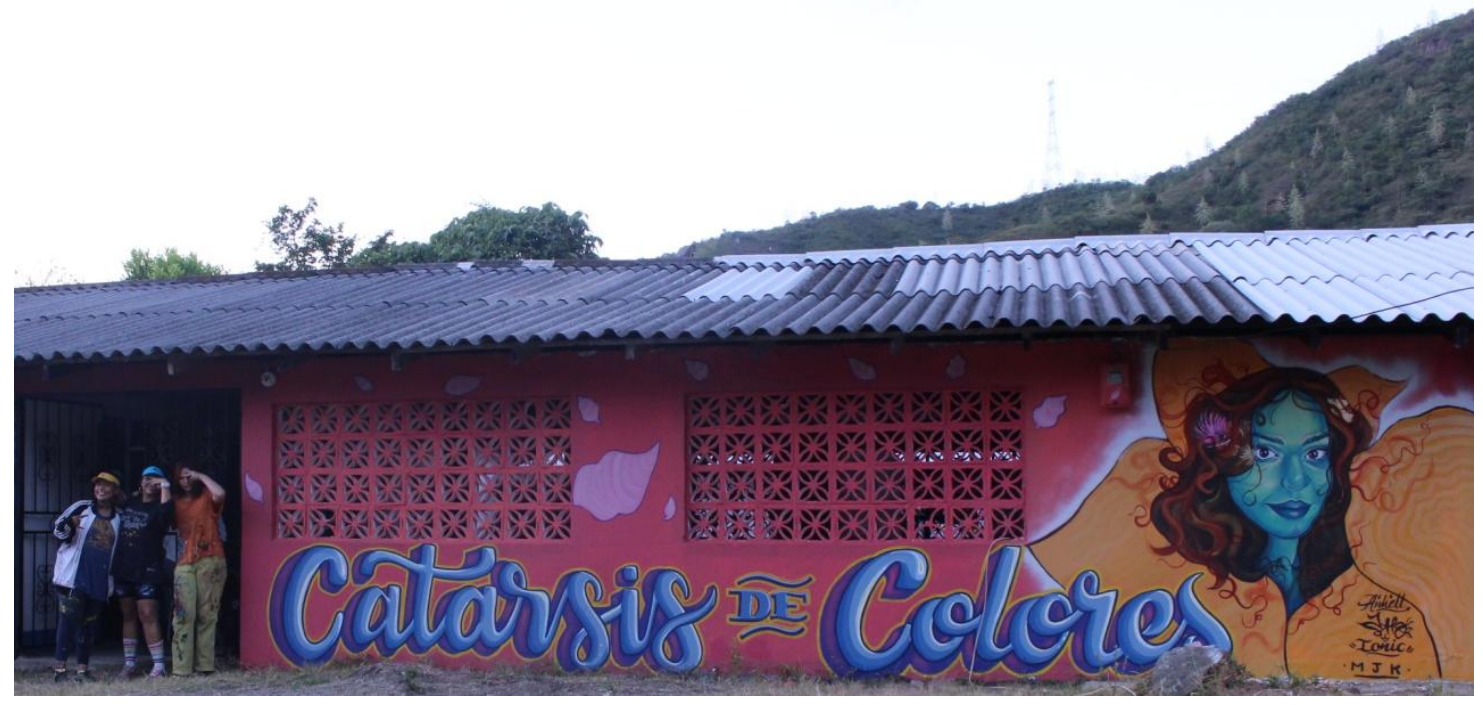

1er minga muralista de mujeres Potrerito, Valle. Mala Junta Klan 
Gutiérrez-Cárdenas

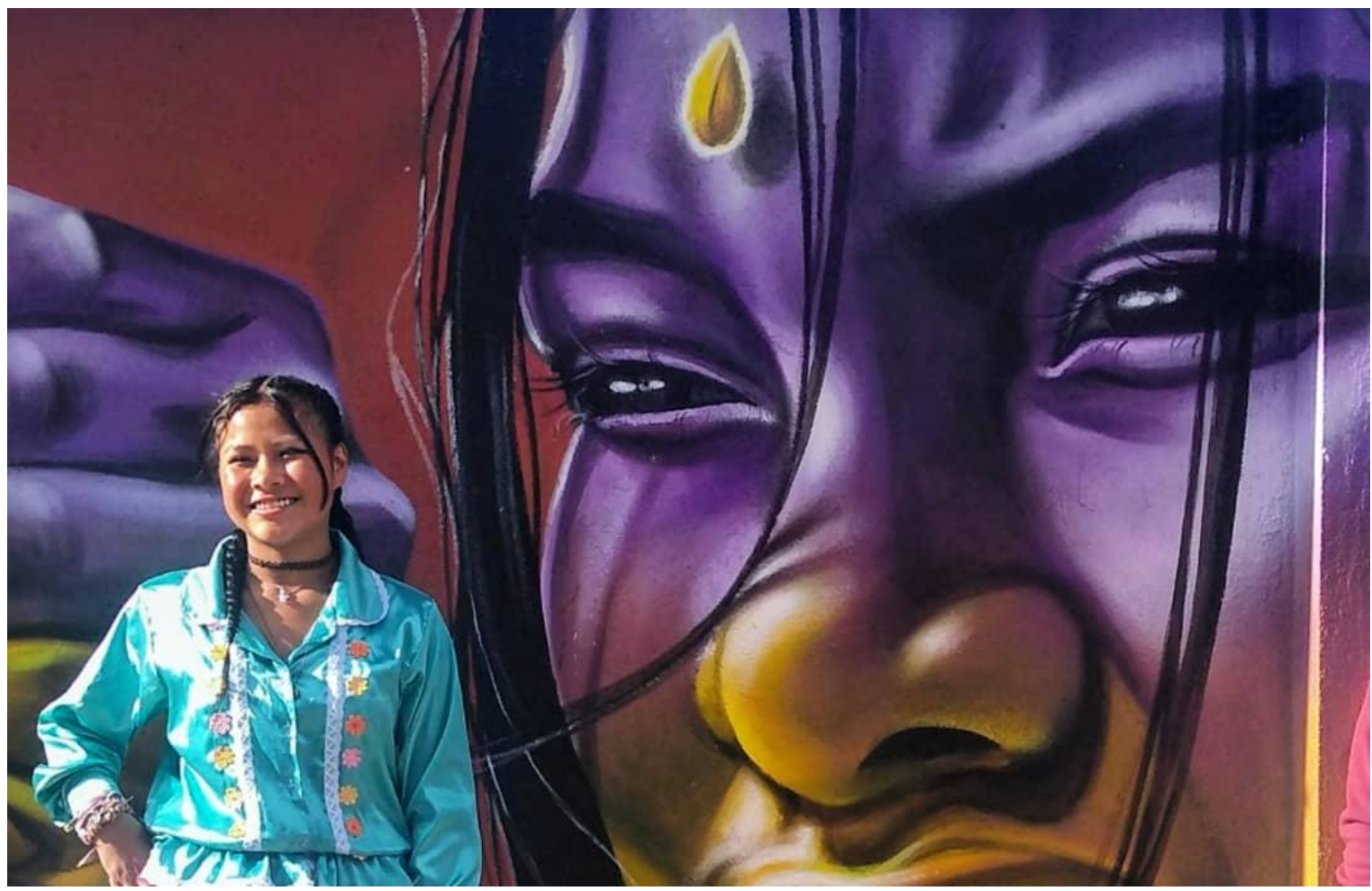

Fotografía de la Minga de muralismo y arte rural y Cueche Jongovito Mala Junta Klan

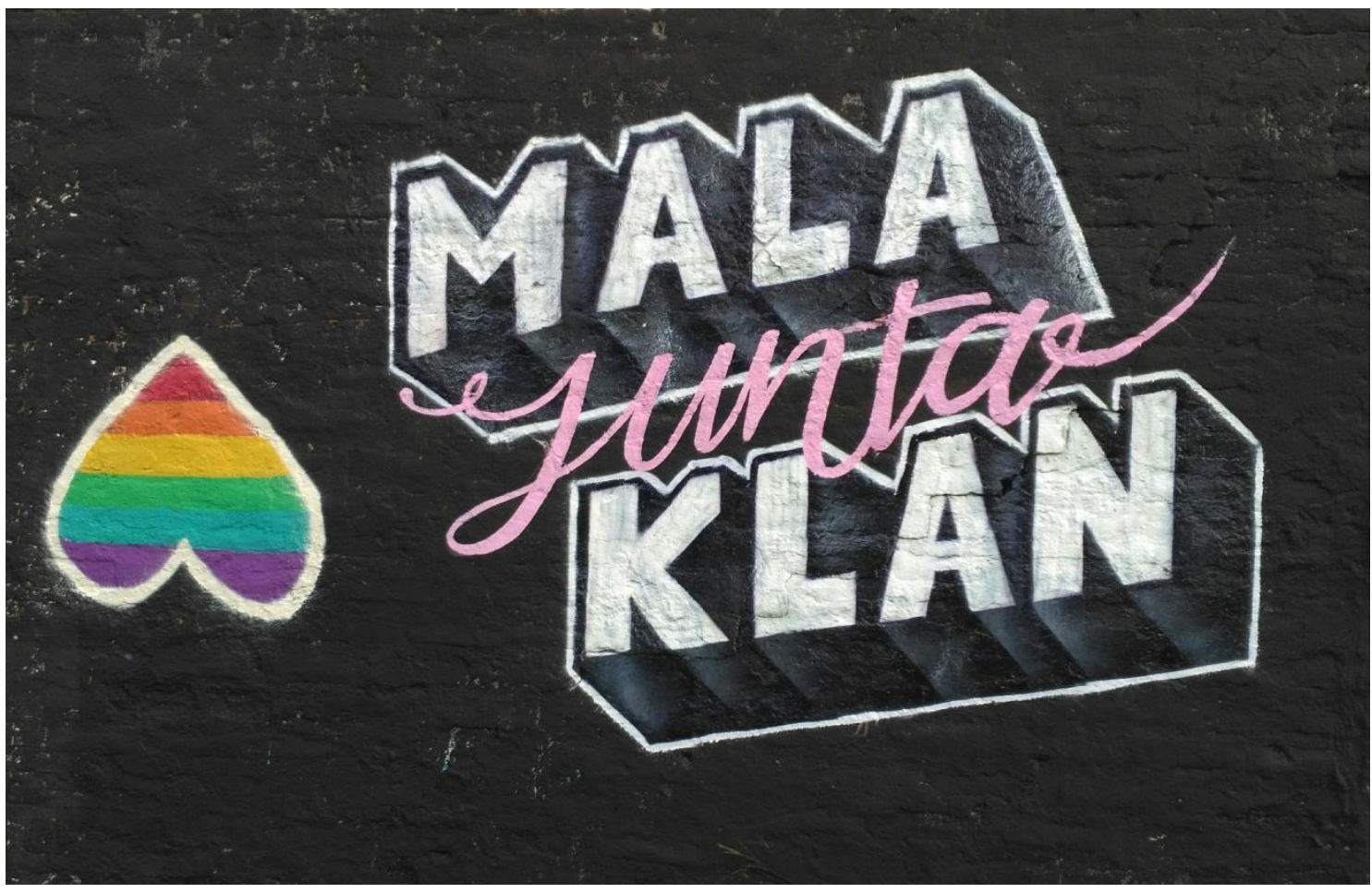

Orgullo

Mala Junta Klan 